\title{
Environmental magnetism: measuring, monitoring and modelling urban street dust pollution
}

C. A. Booth ${ }^{1}$, V. Shilton ${ }^{2}$, M. A. Fullen ${ }^{1}$, J. Walden ${ }^{3}$,

A. T. Worsley ${ }^{4} \&$ A. L. Power ${ }^{4}$

${ }^{1}$ Research Institute in Advanced Technologies (RIATec),

The University of Wolverhampton, West Midlands, U.K.

${ }^{2}$ The Competitiveness Centre, Wolverhampton Science Park,

West Midlands, U.K.

${ }^{3}$ School of Geography \& Geosciences, University of St Andrews, Fife, U.K.

${ }^{4}$ NGAS, Edge Hill University College, Ormskirk, Lancashire, U.K.

\begin{abstract}
Urban street dusts have been monitored monthly for one year (May 2000 to April 2001), their magnetic properties measured and their multivariate relationships modelled by Simultaneous R- and Q-mode Factor Analysis, so as to differentiate dusts from three urban roads (two in Wolverhampton and one in Dudley) in the West Midlands (U.K.). Results show the street dusts contain a large range of magnetic concentrations, magnetic mineralogy and magnetic domain sizes, which has enabled significant differences $(p<0.001)$ to be identified between individual roads. Whilst soil is proposed as a notable provenance for the dust, magnetic values in this study are much higher than those previously reported for topsoils and thus, indicate the influence of other sources, such as anthropogenic pollutants. This indicates the potential of magnetic methodologies as a valuable means of contributing to local and national road pollution monitoring schemes. Furthermore, Factor Analysis aided the interpretation of dust variations and simplified the inter-relationships between magnetic parameters, which highlights its potential for classifying and discriminating urban street dust sources.
\end{abstract}

Keywords: multivariate statistics, anthropogenic pollutants, topsoil, diesel emissions. 


\section{Introduction}

Mineral magnetic analyses are now considered a routine form of analysis when investigating the compositional properties of sediments, soils and dusts [1-3] and have been applied to various environmental settings (e.g. fluvial [4]; lacustrine [5]; desert [6]; glacial [7]; estuarine [8]; coastal [9] and soils [10]). Compared with other analytical methods mineral magnetics provides a compositional tool, which is reliable, rapid, non-destructive, inexpensive and sensitive to low detection levels [11]. Consequently, this has assisted understanding linkages between health and respirable airborne particulate matter [12], association with organic matter $[13,14]$, progressed spatial and temporal pollution studies $[15,16]$, benefited air-borne particulate discrimination $[16,17]$ and highlighted its suitability for aiding biomonitoring of air quality $[18,19]$.

Mineral magnetic data sets are multivariate. However, as the number of samples and parameters increase, it can be increasingly difficult to understand how $\mathrm{n}$ samples are arranged relative to all $\mathrm{m}$ parameters together. Multivariate methods of data analysis are mainly used to provide a visual perception and indication of simultaneous relationships and alliances. Data are simplified, major trends emphasized and minor variations ignored [20]. For example, simultaneous R- and Q-mode factor analysis have discriminated and grouped samples in other environmental contexts $[21,22]$. However, this approach has received little attention as a means of classifying urban street dusts.

Ongoing research is investigating the physico-chemical properties of urban West Midland street dusts, which includes the characterization of their magnetic properties. Within this context, this paper has two objectives: (a) to present initial results on the magnetic properties of urban street dusts and (b) to employ Simultaneous R- and Q-mode Factor Analysis to investigate multivariate relationships of magnetic data and, thus, differentiate urban street dusts.

\section{Study area}

Street dust was collected from three roads within the urban West Midlands, U.K., two roads are located in Wolverhampton City Centre, with the third road in a residential area of Dudley ( $\sim 10 \mathrm{~km}$ south of Wolverhampton): (i) Urban Road 1 (National Grid Reference: SO 391650-298730) - Lichfield Street is the main approach road to the main bus station in Wolverhampton City Centre. The road is closed to most vehicles except buses and taxis; hence buses contribute almost all traffic, with thousands using the route daily $(\sim 2000)$. Frequently, these vehicles are held up at traffic lights at one end of the road, regularly causing queues of vehicles idling outside buildings. Four and five storey buildings on both sides of the road aid a small street canyon effect, which impedes the dispersion of traffic related emissions, thus contributing to high concentrations of airborne particulate matter [23]; (ii) Urban Road 2 (National Grid Reference: SO 391460-298840) - Wulfruna Street is also situated in Wolverhampton City Centre $\sim 200 \mathrm{~m}$ from Urban Road 1. In contrast, this road is only occasionally used by heavy duty vehicles, does not carry high traffic flows and the buildings 
do not produce any significant street canyon effect and (iii) Residential Road (National Grid Reference: SO 393580-291420) - Meadow Road is a residential road in suburban Dudley, which is infrequently used by heavy duty vehicles and carries very low traffic flows, with no local industries nearby.

\section{Methods}

\subsection{Sample collection}

Street dust was collected from six regularly spaced locations along each road on a monthly basis, for one year (May 2000 to April 2001). Typically, dust samples of between 10-50 g were collected by brushing with a small paintbrush inside a $1 \mathrm{~m}^{2}$ quadrat. Dust was transferred to clean, pre-labelled, self-seal, airtight plastic bags. In the laboratory, samples were visibly screened to remove macroscopic traces of hair, animal and plant matter. Samples were then ovendried at $<40^{\circ} \mathrm{C}$ and fractionated through a $63 \mu \mathrm{m}$ sieve. The decision to analyse only the $<63 \mu \mathrm{m}$ fraction was because these particles are easily transported in suspension, with the finest capable of remaining airborne for considerable durations. Samples were then weighed and prepared for analysis [14].

\subsection{Mineral magnetic analyses}

All samples were subjected to the same preparation and analysis procedure [2]. Initial, low-field, mass-specific, magnetic susceptibility $\left(\chi_{\mathrm{LF}}\right)$ was measured using a Bartington MS2 susceptibility meter. By using a MS2B dual frequency sensor, both low and high frequency susceptibility were measured $\left(\chi_{\mathrm{LF}}\right.$ and $\left.\chi_{\mathrm{HF}}\right)$, allowing the frequency dependent susceptibility to be calculated $\left(\chi_{\mathrm{FD}} \%\right)$. Anhysteretic Remanence Magnetisation (ARM) was induced with a peak alternating field of $100 \mathrm{mT}$ and small steady biasing field of $0.04 \mathrm{mT}$ using a Molspin A.F. demagnetizer. The resultant remanence created within the samples was measured using a Molspin 1A magnetometer and the values converted to give the mass specific susceptibility of ARM $\left(\chi_{\mathrm{ARM}}\right)$. Samples were then demagnetized to remove the induced ARM and exposed to a series of successively larger field sizes up to a maximum 'saturation' field of $800 \mathrm{mT}$, followed by a series of successively larger fields in the opposite direction (backfields), generated by two Molspin pulse magnetisers (0-100 and 0 $800 \mathrm{mT})$. After each 'forward' and 'reverse' field, the isothermal remanent magnetisation (IRM) of the sample was measured using the magnetometer. Interpretations of the main parameters used are summarized by Booth et al [10].

\subsection{Multivariate statistical analyses}

All data analyses were performed using MINITAB PC (version 12). Multivariate statistical methods $[24,25]$ are frequently used to analyse mineral magnetic data sets $[21,22]$. In this study, 'Simultaneous R- and Q-mode Factor Analysis' was used. These are based on eigenvector methods and can be performed separately. 
Basically, R-mode methods are similar to Principal Components Analysis [20, 25] and Q-mode methods are very similar to Cluster Analysis but follow a similar procedure to Principal Co-ordinates Analysis [20, 25].

In order to perform R- and Q-mode Factor Analysis, it is first necessary to standardize the raw data matrix to remove the effects of different parameters being measured on different scales. If a common standardization procedure is employed on the raw data matrix prior to the R- and Q-mode analysis, a common set of factors is extracted, and both the parameter factor and sample factor loadings are relative to these same underlying factors $[25,26]$. The loadings can therefore be plotted in the same two-dimensional factor space for any two of these factors. The mathematical procedure, involving a range of basic matrix algebra operations upon the original raw data matrix (of $n$ samples by $m$ parameters), is widely available $[22,25,26]$.

\section{Results and discussion}

\subsection{Magnetic characterization of urban street dust}

Mineral magnetic results are summarized in Table 1. It is notable that the mean $\chi_{\mathrm{LF}}$ value of Urban Road 1 samples $\left(144.22 \times 10^{-7} \mathrm{~m}^{3} \mathrm{~kg}^{-1}\right)$ is significantly greater than both Urban Road $2\left(14.96 \times 10^{-7} \mathrm{~m}^{3} \mathrm{~kg}^{-1}\right)$ and Residential Road samples $\left(15.47 \times 10^{-7} \mathrm{~m}^{3} \mathrm{~kg}^{-1}\right)$. Compared to published values $[13,15,17,27]$, this indicates Urban Road 1 dusts contain very high concentrations of magnetic minerals, greater than nearly all other published values for dust localities. However, in contrast, Urban Road 2 and Residential Road values are lower than most other previously published values. For instance, urban street dust mean $\chi_{\mathrm{LF}}$ value of Liverpool $\left(23.7 \times 10^{-7} \mathrm{~m}^{3} \mathrm{~kg}^{-1}\right)$ is almost twice those of Urban Road 2 , and residential dust mean $\chi_{\mathrm{LF}}$ values of Shanghai $\left(29.9\right.$ and $41.3 \times 10^{-7} \mathrm{~m}^{3} \mathrm{~kg}^{-1}$ ) are almost two to three times greater than those of the Residential Road [27].

Mean Soft percentage and Hard percentage values (Table 1) for each of the roads indicate ferrimagnetic 'magnetite-type' minerals (low coercivity) are more dominant than canted antiferromagnetic 'haematite-type' minerals (high coercivity). Soft percentage values of each road are comparable, whilst the hard percentage value of Urban Road 1 is notably greater than both Urban Road 2 and Residential Road. When these data are compared with other (e.g. [16, 27]) it is noticeable that Soft values (16.8-42.2\%) and Hard values (1.8-15.6\%) of urban dusts (industrial and residential) are also dominated by low coercivity minerals [27]. S-ratio values shows mean values of $\sim-0.7$ for each of the roads, which provides further evidence of a dominance of magnetically soft minerals.

Based on a semi-quantitative mixing model [28] and magnetic interpretations, domain size data indicate all samples from each site contain comparable (coarse stable single domain grains) ferrimagnetic mineral sizes, with the domain size of some Urban Road 1 samples bordering multidomain / pseudo-single-domain sizes. Additionally, the proportion of superparamagnetic grains is typically $10-50 \%$ for each of the roads (Urban Road $1 \sim 60 \%$, Urban Road $2 \sim 65 \%$, and Residential Road $\sim 75 \%$ of the samples) and with some samples (Urban 
Road $1 \sim 20 \%$, Urban Road $2 \sim 30 \%$, and Residential Road $\sim 25 \%$ ) containing virtually no superparamagnetic grains $\left(\chi_{\mathrm{FD} \%} \sim 0-10 \%\right)$. In contrast, $\sim 20 \%$ Urban Road 1 samples contain virtually all superparamagnetic grains $\left(\chi_{\mathrm{FD} \%} \sim 50\right.$ $100 \%)$. Although these data indicate distinct differences between samples and between individual sampling sites, the degree of magnetic domain variation highlighted in this study is notably less than those of Shu et al. [27], who observed urban dust samples to range from virtually all multidomain / pseudosingle-domain grains to virtually all superparamagnetic domain grains.

Table 1: Mean magnetic data and standard deviation (in parentheses) measurements of urban West Midland street dusts.

\begin{tabular}{|c|c|c|c|c|}
\hline $\begin{array}{l}\text { Magnetic } \\
\text { Parameters }\end{array}$ & $\begin{array}{c}\text { All Samples } \\
\mathrm{n}=216\end{array}$ & $\begin{array}{c}\text { Urban Road } \\
1 \mathrm{n}=72 \\
\end{array}$ & $\begin{array}{c}\text { Urban Road } \\
2 n=72\end{array}$ & $\begin{array}{c}\text { Residential Road } \\
\mathrm{n}=72\end{array}$ \\
\hline $\begin{array}{l}\chi_{\mathrm{LF}} \\
\left(10^{-7} \mathrm{~m}^{3} \mathrm{~kg}^{-1}\right)\end{array}$ & $\begin{array}{c}58.83 \\
(84.21) \\
\end{array}$ & $\begin{array}{l}144.22 \\
(99.99) \\
\end{array}$ & $\begin{array}{l}14.96 \\
(0.66) \\
\end{array}$ & $\begin{array}{r}15.47 \\
(0.90) \\
\end{array}$ \\
\hline $\begin{array}{l}\chi_{\mathrm{FD}} \\
(\%) \\
\end{array}$ & $\begin{array}{c}4.37 \\
(4.01) \\
\end{array}$ & $\begin{array}{c}7.00 \\
(5.61) \\
\end{array}$ & $\begin{array}{l}3.10 \\
(2.07) \\
\end{array}$ & $\begin{array}{c}2.95 \\
(1.33) \\
\end{array}$ \\
\hline $\begin{array}{l}\chi_{\text {ARM }} \\
\left(10^{-7} \mathrm{~m}^{3} \mathrm{~kg}^{-1}\right)\end{array}$ & $\begin{array}{c}2.67 \\
(2.03)\end{array}$ & $\begin{array}{c}4.11 \\
(2.00)\end{array}$ & $\begin{array}{c}2.85 \\
(1.62)\end{array}$ & $\begin{array}{c}0.99 \\
(0.91)\end{array}$ \\
\hline $\begin{array}{l}\text { SIRM } \\
\left(10^{-5} \mathrm{Am}^{2} \mathrm{~kg}^{-1}\right)\end{array}$ & $\begin{array}{c}5952.99 \\
(5301.17)\end{array}$ & $\begin{array}{l}11005.55 \\
(5364.36)\end{array}$ & $\begin{array}{l}4962.96 \\
(2898.97)\end{array}$ & $\begin{array}{c}1711.23 \\
(1570.13)\end{array}$ \\
\hline $\begin{array}{l}\text { SOFT } \\
(\%)\end{array}$ & $\begin{array}{l}17.59 \\
(3.17) \\
\end{array}$ & $\begin{array}{l}17.40 \\
(5.32) \\
\end{array}$ & $\begin{array}{r}17.73 \\
(1.04) \\
\end{array}$ & $\begin{array}{l}17.63 \\
(0.82) \\
\end{array}$ \\
\hline $\begin{array}{l}\text { HARD } \\
(\%)\end{array}$ & $\begin{array}{c}4.27 \\
(5.97)\end{array}$ & $\begin{array}{c}8.57 \\
(8.37)\end{array}$ & $\begin{array}{c}2.48 \\
(2.26)\end{array}$ & $\begin{array}{c}1.65 \\
(1.57)\end{array}$ \\
\hline $\begin{array}{l}\text { S-ratio } \\
\text { (none) }\end{array}$ & $\begin{array}{l}-0.76 \\
(0.08)\end{array}$ & $\begin{array}{l}-0.78 \\
(0.12)\end{array}$ & $\begin{array}{l}-0.76 \\
(0.02)\end{array}$ & $\begin{array}{l}-0.73 \\
(0.04)\end{array}$ \\
\hline $\begin{array}{l}\mathrm{ARM} / \chi \\
\left(10^{-2} \mathrm{Am}^{-1}\right)\end{array}$ & $\begin{array}{c}3.20 \\
(3.26) \\
\end{array}$ & $\begin{array}{c}1.34 \\
(1.21) \\
\end{array}$ & $\begin{array}{c}6.16 \\
(3.59) \\
\end{array}$ & $\begin{array}{c}2.07 \\
(1.96) \\
\end{array}$ \\
\hline $\begin{array}{l}\text { SIRM/ARM } \\
\text { (none) }\end{array}$ & $\begin{array}{c}64.45 \\
(15.25) \\
\end{array}$ & $\begin{array}{l}84.36 \\
(8.51) \\
\end{array}$ & $\begin{array}{l}54.21 \\
(3.09) \\
\end{array}$ & $\begin{array}{l}54.36 \\
(2.23) \\
\end{array}$ \\
\hline $\begin{array}{l}\mathrm{SIRM} / \chi \\
\left(10^{-2} \mathrm{Am}^{-1}\right)\end{array}$ & $\begin{array}{c}187.30 \\
(177.73)\end{array}$ & $\begin{array}{l}110.25 \\
(94.41)\end{array}$ & $\begin{array}{c}336.44 \\
(201.44)\end{array}$ & $\begin{array}{c}112.03 \\
(105.90)\end{array}$ \\
\hline $\begin{array}{l}\chi_{\text {ARM }} / \mathrm{SIRM} \\
\left(10^{-5} \mathrm{Am}^{-1}\right)\end{array}$ & $\begin{array}{c}0.51 \\
(0.10) \\
\end{array}$ & $\begin{array}{c}0.38 \\
(0.04)\end{array}$ & $\begin{array}{c}0.58 \\
(0.04)\end{array}$ & $\begin{array}{c}0.58 \\
(0.02) \\
\end{array}$ \\
\hline
\end{tabular}

\subsection{Magnetic differentiation of urban street dust}

To determine any evidence of significant variations between each of the sample sites, ANOVA F-tests were performed (Table 2). With the exception of SOFT\%, the sample site populations for each parameter significantly differ $(n=216$; $\mathrm{p}<0.001)$. However, variations of temporal analyses are statistically insignificant and reveal no apparent trends (data not presented).

Factor analysis was then performed using all mineral magnetic parameters. The first two factors extracted explain $68.0 \%$ of the variation in all of the nine original parameters. Parameter and sample loadings extracted from Factors 1 and 2 were used to generate a factor plot (Figure 1). Factor 1 explains $40.8 \%$ of the 
variation in the parameters and consequently, several parameters are related to this factor. The $\chi_{\mathrm{LF}}$, Hard and SIRM/ARM parameters have positive loadings on Factor 1 , and the $\chi_{\mathrm{ARM}} / \mathrm{SIRM}$ parameter has negative loadings on Factor 1. Factor 2, on the other hand, explains $27.2 \%$ of the variation in the parameters, and the $\mathrm{SIRM} / \chi, \mathrm{ARM} / \chi$ and SOFT parameters have positive loading on Factor 2 and the S-ratio has negative loadings on Factor 2.

Table 2: $\quad$ ANOVA $F$-test analyses from the urban West Midland street dust populations, values show $F$-calculated $(F$-critical $=3.04 ; \mathrm{p}<0.05)$ and the significance level for each magnetic parameter $\left({ }^{\mathrm{NS}}=\right.$ not significant).

\begin{tabular}{|c|c|c|c|c|c|}
\hline $\begin{array}{l}\text { Magnetic } \\
\text { Parameters }\end{array}$ & $\begin{array}{c}F- \\
\text { calculated }\end{array}$ & $P$-value & $\begin{array}{l}\text { Magnetic } \\
\text { Parameters }\end{array}$ & $\begin{array}{c}F- \\
\text { calculated }\end{array}$ & $P$-value \\
\hline$\chi_{\mathrm{LF}}$ & 115.65 & $<0.001$ & S-ratio & 10.19 & $<0.001$ \\
\hline$\chi_{\mathrm{FD} \%}$ & 29.41 & $<0.001$ & $\mathrm{ARM} / \chi$ & 78.16 & $<0.001$ \\
\hline$\chi_{\text {ARM }}$ & 67.70 & $<0.001$ & SIRM/ARM & 724.19 & $<0.001$ \\
\hline SIRM & 116.13 & $<0.001$ & $\mathrm{SIRM} / \chi$ & 58.58 & $<0.001$ \\
\hline SOFT $_{\%}$ & 0.20 & $0.815^{\text {N.S. }}$ & $\chi_{\text {ARM }} /$ SIRM & 868.11 & $<0.001$ \\
\hline $\mathrm{HARD}_{\%}$ & 38.30 & $<0.001$ & & & \\
\hline
\end{tabular}

From the spread of the sample loadings, samples are strongly influenced by both Factors 1 and 2. However, sample spread along Factor 1 axis has separated Urban Road 1 samples from those of both Urban Road 2 and Residential Road samples. Consequently, Urban Road 1 samples have positive Factor 1 loadings and both Urban Road 2 and Residential Road samples have negative Factor 1 loadings. Therefore, it is inferred, those parameters positioned at opposite ends of the Factor 1 axis are appropriate for differentiating urban street dusts of the West Midlands. This suggests R- and Q-mode Factor Analysis can successfully be applied as a rapid and useful means of assessing which analytical parameters can be used to discriminate dust sample populations.

\subsection{Source ascription of urban street dusts}

A principal application of the mineral magnetic approach is the elucidation of sediment-source-linkages [1-3]. In many magnetic provenance studies qualitative statements are frequently proposed for probable sources [21, 22].

Typically, superparamagnetic and stable single domain size grains dominate free-draining surface soils and therefore, are proposed as the principal source for the street dusts. This interpretation is similar to Xie et al. [31], who identified surface soils as being the dominant source of street dusts in the City of Liverpool. Magnetic pedological studies $[29,30]$ have shown the mean $\chi_{\mathrm{LF}}$ and $\chi_{\mathrm{FD} \%}$ of topsoils to be $7.3 \times 10^{-7} \mathrm{~m}^{3} \mathrm{~kg}^{-1}$ and $4.1 \%$, respectively. Comparison of our results to these data shows dusts from Urban Road 2 and Residential Road are similar to typical topsoils. However, mean $\chi_{\mathrm{LF}}$ and $\chi_{\mathrm{FD} \%}$ values for Urban Road 1 are considerably higher than typical topsoils. This suggests that, in 
addition to surface soils, Urban Road 1 dusts must contain a sizeable contribution of other sources of magnetic minerals. Compared to typical vehicular derived values dusts [15], Urban Road 1 values are within the typical range of this source. Therefore, it is further proposed, vehicular derived particles represent a second dust source.
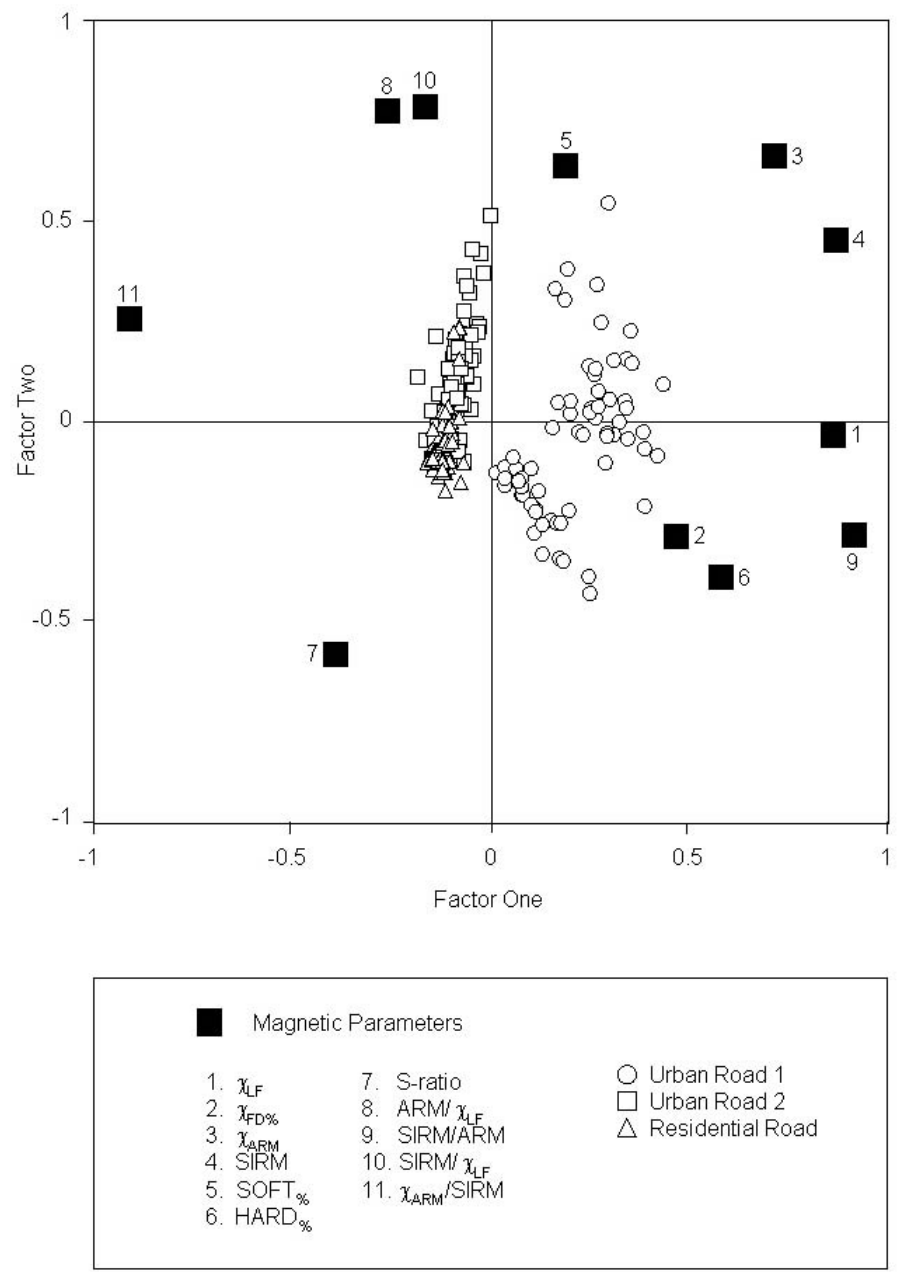

Figure 1: $\quad$ Simultaneous R- and Q-mode Factor Analysis plot of Factor 1 versus Factor 2, showing the relationship between the three roads, based on the magnetic characteristics of the samples.

SEM dust analyses show Urban Road 1 contain Fe-rich, spherical particulates. Sphericule sizes $(0.2-2 \mu \mathrm{m})$ are similar to pseudo-single-domain grains $(0.7-10 \mu \mathrm{m})$. Hanesch and Petersen [32] used electron microscopy to 
demonstrate the presence of combustion-generated, metallic spherules in brown earths. Therefore, it is plausible the source of coarse stable-single-domain grains is an anthropogenic pollutant, particularly as Urban Road 1 has restricted access and several thousand diesel engine buses use the route daily. Therefore, the likely source is diesel emissions.

\section{Conclusions}

Urban West Midland street dusts contain a large range of magnetic concentrations, magnetic mineralogy and magnetic domain size characteristics, with some values much greater than similar published work, which has enabled notable differences to be identified between individual roads. It is inferred that magnetic measurements offer a viable approach to distinguish urban street dusts and, thus, indicates the potential of magnetic methodologies as a valuable means of contributing to local and national road pollution monitoring schemes.

Simultaneous R- and Q-mode Factor Analysis aided the interpretation of the nature of urban street dusts variations and simplified the inter-relationships between magnetic parameters. However, this work also highlights that this form of multivariate data analysis, applied to atmospheric magnetism data, shows considerable potential for classifying and discriminating urban street dusts.

\section{Acknowledgements}

This research was supported by a University of Wolverhampton studentship, awarded to Vaughan Shilton, who also gratefully acknowledges the receipt of the CN Davies Award from the Aerosol Society. VS also thanks his supervisory team, Dr P. Giess, Prof. D.J. Mitchell and Prof. C. Williams, for their guidance.

\section{References}

[1] Thompson, R. \& Oldfield, F., Environmental Magnetism. Allen \& Unwin, London, England, pp. 227, 1986.

[2] Walden, J., Smith, J.P. \& Oldfield F., (Eds.) Environmental Magnetism, A Practical Guide. Q.R.A., Technical Series No. 6., pp. 243, 1999.

[3] Maher, B.A. \& Thompson, R., (Eds.), Quaternary Climates, Environments and Magnetism, Cambridge Uni. Press, pp. 383, 1999.

[4] Desenfant, F., Petrovsky, E. \& Rochette, P., Magnetic signature of industrial pollution of stream sediments and correlation with heavy metals: case study from South France. Water, Air \& Soil Pollution, 152, pp. 297-312, 2004.

[5] Magiera, T., Strzyszcz, Z. \& Kostecki, M., Seasonal changes of magnetic susceptibility in sediments from Lake Zyweic (south Poland). Water, Air \& Soil Pollution, 141, pp. 55-71, 2002.

[6] White, K., Walden, J., Drake, N., Eckardt, F. \& Settle, J., Mapping the iron oxide content of dune sands, Namib Sand Sea, Namibia, using 
Landsat Thematic Mapper data. Remote Sensing of the Environment, 62, pp. 30-39, 1997.

[7] Walden, J., Smith, J.P., Dackombe, R.V. \& Rose, J., Mineral magnetic analyses of glacial diamicts from the Midland Valley of Scotland. Scottish Journal of Geology, 31, pp. 79-89, 1995.

[8] Booth, C.A., Walden, J., Neal, A., Smith, J.P., \& Morgan, E., A comparison of inter-unit, intra-site and intra-sample variability in environmental magnetic data: an example based on the Gwendraeth Estuary, South Wales, U.K. Journal of Coastal Research, 20, pp. 808-813, 2004.

[9] Booth, C.A., Walden, J., Neal, A., \& Smith, J.P., Use of mineral magnetic concentration data as a particle size proxy: a case study using marine, estuarine and fluvial sediments in the Carmarthen Bay area, South Wales, U.K. Science of the Total Environment, 347, pp. 241-253, 2005.

[10] Booth, C.A., Fullen, M.A., Smith, J.P., Hallett, M.D., Walden, J., Harris, J., \& Holland, K., Magnetic properties of agricultural topsoils of the Isle of Man: their characterisation and discrimination by factor analysis. Communications in Soil Science \& Plant Analysis, 36, pp. 1241-1262, 2005.

[11] Walden, J., Smith, J.P. \& Dackombe, R.V., A comparison of mineral magnetic, geochemical and mineralogical techniques for compositional studies of glacial diamictons. Boreas 25, pp. 115-130, 1996.

[12] Morris, W.A., Versteeg, J.K., Bryant, D.W., Legzdins, A.E., McCarry, B.E. \& Marvin, C.H., Preliminary comparisons between mutagenicity and magnetic susceptibility of respirable airborne particulate. Atmospheric Environment, 29, pp. 3441-3450, 1995.

[13] Xie, S., Dearing, J.A. \& Bloemandal, J., The organic matter content of street dust in Liverpool, UK and its association with dust magnetic properties. Atmospheric Environment, 34, pp. 269-275, 2000.

[14] Shilton, V.F., Booth, C.A., Giess, P., Mitchell, D.J., \& Williams, C.D., Magnetic properties of urban street dust and its relationship to organic matter content in the West Midlands, U.K. Atmospheric Environment, 39, pp. 3651-3659, 2005.

[15] Beckwith, P.R., Ellis, J.B., Revitt, D.M. \& Oldfield, F., Heavy metal and magnetic relationships for urban source sediments. Physics of the Earth Planetary Interiors, 42, pp. 67-75, 1986.

[16] Hoffmann, V., Knab, M. \& Appel, E., Magnetic susceptibility mapping of roadside pollution. J. Geochem. Exploration, 66, pp. 313-326, 1999.

[17] Hunt, A., The application of magnetic methods to atmospheric aerosol discrimination, Physics Earth \& Planet. Interiors, 42, pp. 10-21, 1986.

[18] Matzka, J. \& Maher, B.A., Magnetic biomonitoring of roadside tree leaves: identification of spatial and temporal variations in vehicle derived particulates. Atmospheric Environment, 33, pp. 4565-4569, 1999.

[19] Moreno, E., Sagnotti, L., Dinares-Turall, J., Winkler, A. \& Cascella, A., Biomonitoring traffic air pollution in Rome using magnetic properties of tree leaves. Atmospheric Environment, 37, pp. 2967-2977, 2003. 
[20] Kovach, W.L., Multivariate data analysis. In: D. Maddy \& J.S. Brew (Eds.) Statistical Modelling of Quaternary Science Data, Q.R.A. Technical Series No. 5, pp. 1-38, 1995.

[21] Walden, J., Smith, J.P. \& Dackombe, R.V., The use of simultaneous Rand Q-mode factor analysis as a tool for assisting interpretation of mineral magnetic data. Mathematical Geology, pp. 24, 227-247, 1992.

[22] Walden, J. \& Smith, J.P., Factor analysis: a practical application. In: D. Maddy \& J.S. Brew (Eds.) Statistical Modelling of Quaternary Science Data, Q.R.A. Technical Series No. 5, pp. 39-64, 1995.

[23] Giess, P., Respirable particulates and oxides of nitrogen measured inside buildings alongside a busy road. Indoor Built Environment, 7, pp. 308314, 1998.

[24] Manly, B.F.J., Multivariate Statistical Methods: A Primer, Chapman \& Hall, London, pp. 215, 1994.

[25] Davis, J.C., Statistics and Data Analysis in Geology, John Wiley \& Sons, Chichester, England, pp. 638, 2002.

[26] Zhou, D., Chang, T. \& Davis, J.C., Dual extraction of R-mode and Qmode factor solutions. Journal of the International Association of Mathematical Geology, 15, pp. 581-606, 1983.

[27] Shu, J., Dearing, J.A., Morse, A.P., Yu, L. \& Yuan, N., Determining the source of atmospheric particles in Shanghai, China, from magnetic geochemical properties. Atmospheric Environment, 35, pp. 2615-2625, 2001.

[28] Dearing, J.A., Bird, P.M., Dann, R.J.L. \& Benjamin, S.F., Secondary ferrimagnetic minerals in Welsh soils: a comparison of mineral magnetic detection methods and implications for mineral formation. Geophysical Journal International, 130, pp. 727-736, 1997.

[29] Dearing, J.A., Dann, R.J.L., Hay, K., Lees, J.A., Loveland, P.J. \& O'Grady, K., Frequency-dependent susceptibility measurements of environmental materials. Geophysical Journal International, 124, pp. 228-240, 1996.

[30] Hay, K.L., Dearing, J.A., Baban, S.M.J. \& Loveland, P., A preliminary attempt to identify atmospherically-derived pollution particles in English topsoils from magnetic susceptibility measurements. Physics \& Chemistry of the Earth, 22, pp. 207-210, 1997.

[31] Xie, S., Dearing, J.A., Bloemandal, J. \& Boyle, J.F., Association between the organic matter content and magnetic properties in street dust, Liverpool, U.K. Science of the Total Environment, 241, pp. 205-214, 1999.

[32] Hanesch, M. \& Peterson, N., Magnetic properties of a recent parabrownearth from southern Germany. Earth \& Planetary Letters, 169, pp. 85-87, 1999. 